\title{
Mobility and belonging - A case from provincial Denmark
}

\author{
John Gulløv, Eva Gulløv
}

Abstract: Young people in rural areas are gradually convinced that they have to leave their homes for education. They move, and hereby amplify the problem of local economic and demographic decline. The article explores the role of education as well as the social dynamics behind this process in a minor community in Denmark. Drawing on children and young people's perspectives, the article examines how children gradually come to doubt on the local opportunities and become alienated to local lifeforms. Based on an anthropological fieldwork, the authors show how day-care institutions, schools and youth education play an important role in this process.

Keywords: learning to leave, rural upbringing in Denmark, role of education

\section{Introduction}

Every year many high-school students leave the Danish provinces to study at universities or university colleges in Denmark's five major cities. Eventually, many of them come to identify with urban lifestyles and establish themselves with new social networks, families and jobs far away from the geographical spaces of their childhood. Accordingly, the number of young people living in the provinces is declining - as is the relative level of education outside the major cities. Although this pattern has a specific Danish history, it is also part of a global trend described as a 'mobility imperative' that prompts young people in rural districts to migrate to the main cities of the world (Farrugia 2016). This is a tendency that reflects powerful pull factors formed by an accelerating concentration of economic and cultural capital in the cities. But as we will show, there are also significant push factors owing to the influence of the education system on local social distinctions. 
This article addresses the way in which the mobility of young people relates to the education system in Denmark. We explore how schools and higher education influence the trajectory of individual children and young people in significant ways - as well as their perception of what is worth striving for. Drawing on data from ethnographic fieldwork conducted in the southwestern part of Denmark in 2016, we will focus on the values and practices that convince young people to leave their home region. We are interested in the processual development of distinctions and symbolic boundaries that develop as children adapt to the prevailing demands of the education system. In short, the gradual change in their orientations and commitments from local values and opportunities towards new places and educational merits is a process which makes geographical mobility inevitable and preferable. In order to study this process of changing attitudes, we have developed a multigenerational approach involving parents, young children, schoolchildren and high-school students, focusing in particular on how local and urban orientations change across different age groups with respect to different local and educational strategies (Gulløv \& Gulløv 2020).

The analysis is inspired by the studies conducted by Michael Corbett on the role of school in rural settings $(2007,2014)$. Based on statistical and historical documents from Nova Scotia, Canada, he demonstrates that schools play a significant role in how children learn to leave rural areas, as their main purpose is to pave the way for further education elsewhere. The studies conducted by Pierre Bourdieu have also improved the analysis. In his studies of French society, Bourdieu shows that places are attributed more or less prestige, and how this has implications for people's decision to stay or leave (Bourdieu 2004 [1962], 1996). He also points out that the education system is a main distributer of symbolic resources in contemporary society (1974); a fact that makes it urgent for young people to get an education even if this means moving away. All in all, formal schooling and education play a central role in the production of dominant social distinctions and power relations, a point which is particularly relevant in understanding the uneven socio-geographical distribution of symbolic capital in contemporary societies, with success in the education system being linked explicitly to urban, middle-class ways of living (Corbett and Forsey 2017).

These approaches are important if we are to understand why we see an increasing orientation towards urban lifestyles among the oldest of our young informants. However, it is important to stress that not all young people follow the established pathway of education; and that not all of the young peo- 
ple who do leave their home region find the decision easy or unambiguous. Nevertheless, a significant number of students leave the provinces in favour of the cities - not only because they are attracted by urban life, but, as we will show, also because they are pushed by the fear of being stigmatised as failures if they remain in the place where they grew up. Education becomes entwined with ambitions and distinctions that affect people's confidence in their options if they remain in their local communities. In other words, children's experiences of school, local places and social networks have consequences not only for their individual social, educational and geographical perceptions and preferences, but also for the cohesion and future of local communities (Gulløv \& Gulløv 2020).

\section{Presentation of The Study and The Site of our Fieldwork}

As discussed by geographers and sociologists, any place is a practised space and it is formed through people's interpretations and activities. Places make sense when people invest in them, attribute meaning to them and build affiliations (e.g. Massey 1994, 2015; Manzo \& Devine-Wright 2014). From this perspective, local spaces will be perceived differently according to the various experiences and positions people hold, and this has implications for whether they feel attached to a place or motivated to stay or leave. In order to allow for this factor, we needed to develop a research design that was sensitive to the ways people look upon and feel about the places they live in, and how they identify with or distance themselves from specific localities and compare them to places elsewhere. More particularly, and inspired by anthropological and sociological child research, we wanted to know how children and young people perceive places, opportunities and social commitments as a way to understand their various motives and motivations in relation to local communities. However, we also wanted to explore enculturation processes and the social dynamics of wider society from a new angle (Toren 1993; Levinson, Foley \& Holland 1996; Corsaro 1997; Gilliam $\&$ Gulløv 2019). This called for an ethnographic study based in a provincial community, and we, therefore, decided to conduct our fieldwork in the municipality of Tønder in the southwestern part of Denmark, as this region is marked by a high emigration rate among young people. Our point of departure was the main town of Tønder, a settlement of around 7,500 inhabitants dating back to the 13th century. The first phase of our fieldwork was conducted over 31/2 months from late March to July 2016, with several follow-up visits (the last of which was in March 2019). 
Methodologically the design involved ethnographic observations of and conversations with young children in two kindergartens, one in a small village and one in the town of Tønder, as well as interviews with 12 of their parents. In these interviews we were curious to learn why these parents had decided to settle and raise children in the area, and to find out what they thought about future opportunities for their children. We conducted focus group interviews with 45 children aged 11-14 in three different schools, asking them about their hopes and aspirations, attachments and experiences of school. Additionally, we interviewed 10 students in high school (gymnasium in Danish) to find out what they thought about their future opportunities locally and elsewhere. Furthermore, we interviewed 28 people working as childcare professionals, teachers, managers and counsellors in kindergartens, schools, high schools and the various education programmes available in the region. The aim was to make them reflect on the role of schooling and their own work as professionals in relation to both the future of young people and the local region. Our interviews with parents and young people in high school as well as our observations of kindergarten children are particularly central to our argument here. Specifically, our aim is to understand why about $90 \%$ of high-school students in rural areas leave their local region. We wanted to study the formative social processes that lead some youngsters to see education as the principal way to provide a secure future for themselves, even though it requires them to disregard their local attachment.

With a view to explaining why education may interfere with a local future for young people, a short note on regional developments in Denmark is necessary. In the last decades of the $20^{\text {th }}$ century the Danish state wanted to integrate municipalities and counties into a more efficient centralised national organisational structure. The subsequent centralisation of state institutions in the main cities led to a substantial decline in public jobs in the provinces. It also led to a reduced local political and administrative autonomy. Due to these measures as well as changes in agricultural production, the region of Tønder has faced a significant decline in trade, economy and jobs. Small towns and villages are now suffering from falling house prices, closed shops and enterprises, decaying buildings, and lower average income levels compared with national standards. There has also been a demographic change where newcomers tend to be migrants, elderly or unemployed people searching for cheap housing and incidental jobs while young people are likely to leave (Kontur 2019). As almost all kinds of higher education have been centralised in the main cities of Denmark, a significant number of young people move away when they are about 20 years old - and many of them do not return. 


\section{A Short Note on the Education System in Denmark}

A characteristic feature of the Danish welfare state is the amount of time most Danish children spend in public institutions from an early age. In 2015, 89.7 per cent of all children aged 6 months to 2 years children in Denmark attended out-of-family care in public-funded nurseries or small at-home day-care facilities, while 97.5 per cent of all 3-5 year-olds were enrolled in public kindergartens. Whereas childcare institutions for younger children are optional, school is compulsory from the age of 6 and lasts for 10 years. In $201578.8 \%$ of all Danish schoolchildren attended state comprehensive schools, which are free of charge and cater for 6-16 year-olds. $19.2 \%$ attended either private schools or independent schools established by parents and teachers, usually based on specific educational or religious ideas. Both of these alternatives are dependent on parental fees but are subsidised by the state. Regardless of type, all schools must adhere to the goals set by national and municipal authorities.

When they leave school, young people can choose a course of uppersecondary education, which (like comprehensive school) is free of charge. Although upper-secondary education is optional, huge efforts are made to persuade as many young people as possible to continue either on one of the 102 practical programmes in a vocational college, or in a high school. The Danish high-school programme comes in three categories - all taking three years and preparing students for university studies: STX (the classic high school, Gymnasium, which is by far the most popular), HTX (the technical line), and HHX (the commercial line). In 2018 72\% of the young generation applied for a high-school programme (in 1980 this figure was only 33\%), and only $20 \%$ for a vocational programme. $8 \%$ did not attend any formal uppersecondary education.

Higher education comprises a variety of programmes and disciplines which vary in terms of their length and structure. Until 2008 many Bachelor's programmes like teacher-training courses and nursing courses were offered by 120 small-scale non-university institutions scattered throughout the country. After reforms in 2008, all higher education programmes were centralised and are now offered by eight universities and six university colleges. Although some university colleges are based in the provinces, courses of higher education are generally located in the main cities.

The overall picture in Tønder differs slightly from the national picture. In Tønder $61.5 \%$ of the young generation enrol at one of the three high schools, 
$26.4 \%$ enroll for vocational training, and $12 \%$ leave school without further education or postpone the decision until later in life. All courses of uppersecondary education are located in the town of Tønder. There are only a few vocational programmes - only four introductory programmes out of a total of 102 - and all the students need to finish the second part of their programme in other regional cities at least $60-80 \mathrm{~km}$ away. In short, three local institutions offer the full high-school programme, but there are only a few local options for vocational training.

In the next sections we will present our analysis of the reasons why so many young people choose to leave their local community, particularly those attending the STX high school, the classic line. Our main point is that this tendency reflects not only structural imbalances and the opportunities and attractions of urban life, but also a social dynamic among peers: a concern about being disregarded locally, a fear of being seen as backward or failing, as someone being left on the periphery of society despite local attachments and opportunities. We open the analysis with some of the reflections presented by young parents who have recently chosen to stay or return to their local community.

\section{Young Parents' views of Local Society}

Despite differences in educational background, work experiences and geographical biography, the parents we interviewed speak in positive terms about the local community. Most of them were born and raised in the region, some have moved to their spouses' place of birth, but they all underline that they regard Tønder as a fine place to raise children. They emphasise the opportunity for children "to move around freely", the "safe environment" and "peace and quiet", and those who have family living nearby stress how valuable this is.

Though none of the parents in our interviews are well-off - actually, it is clear that some of them have a relatively tight financial situation because only one in the household is in employment - they all have good homes, feel locally respected and seem integrated in social networks. Some work as builders or small-scale farmers in addition to whatever paid jobs they can find, some have their own businesses, and quite a few have part-time or fulltime employment in private companies or in the public sector. Only one has attended higher education, and she finds it difficult to match her qualifications with local job opportunities. 
Although they are busy taking care of their young children, housework and jobs, most of them also find time to invest in local activities and to build relationships with others who may have very different lifestyles, backgrounds and values. They engage in the boards of their children's institutions, as volunteers in sports clubs, in the local business association, as participants in church work, or in one or more of the countless associations existing in the area. They organise or participate in local activities, or contribute as helpers at festivals and events that take place on a regular basis. Although both Lars and his wife have a lot to do, he explains how happy he is that they have moved back to the area, and how important he thinks it is to support and invest in local activities:

Lars: Those who have been away and moved back like us do it because they are devoted to this place. They get involved. Sports clubs don't come from nothing. They come because people want them. And I feel that there is a great will to do so. We know very well that we will get nothing for free here in Tønder. Almost everything depends on volunteers. (...) After all, it's shoulders like ours that it all depends on. It's our generation. We are very aware of this. (...) And I also think that our children should feel our commitment.

Christian, who comes from a small town in the area, also emphasises the importance of local engagement. Although he has full-time work and is the father of five, he attends the boards of the kindergarten and local school, as well as being on the committee for village parties. He is the coach of the local children's football team and is involved in the local civic centre. He explains that he finds the effort worthwhile because it makes it possible "to know who your children are with" and to "influence the institutions your children attend".

Not only the parents we interviewed, but also parents we met and conversed with during various arrangements, stress the importance of local network. Some have found jobs or a place to live through their social contacts, and all of them say that they use their network to exchange services or goods. Having a strong local network seems to be a form of social capital that increases the benefits and potentials of living in the area. They all know that social contacts can be drawn on if help and collaboration is needed in various situations, but they also know that it takes effort to build and maintain relationships. As also pointed out by Noel Dyck (2002) in a study of parental involvement in children's sporting activities, investing in the social life in a specific locality supports and reinforces experiences of cohesion and community beyond the specific situations. It is through 
this that place attachments are formed and maintained (Manzo \& DevineWright 2014).

Despite the fact that the parents - not least because of their social networks - all seem to have a life they are satisfied with, several of them are concerned for the local economy in the future. When asked about the local prospects for their children, they often seem indecisive, and their answers are hesitant or even pessimistic. Some are quite convinced that their children will not be able to stay when they come of age. As Christina says: "There isn't much to do here". She herself has a degree in nutrition, and commutes quite a distance every day to do a job "where I can use my education". And Sara, reflecting on the options for her children in the future, states: "It is really important that you get an education. After all, they have to be able to look after themselves - that is, to manage themselves". Sara has a short term degree in accounting, which required her to drive two-hours daily as she did not want to move out of the area. Although she was able to stay in the area while taking her education and later managed to get a job through her connections, she doesn't think the same will be possible for the next generation. "I don't think there is a chance that my children will stay here. I don't think so". Simone, a young mother with two girls, also managed to commute to take a short-term course of higher education. She has never needed her formal qualifications, as she found an altogether different kind of local job through one of her mother's acquaintances. Nevertheless, she is convinced that her daughters will have to move: "This is what it's like when you choose to settle down here. After all, you have to have an education". Despite Sara's and Simone's personal experiences of social network being of more importance than their educational qualifications, they have little faith that this network can guarantee a safe future for their children.

Some of the parents we interviewed never intended to move away from their local district, while others who moved decided to return though they knew that many of their friends had left. Some explain that they felt a certain pressure to leave and experienced a sense of doubt owing to the expectations of their peers and advice from their teachers and counsellors. Such experiences are mirrored in the double strategies they adopt for their children: on one hand they are eager to see their children fully integrated in the local community, while on the other they tell them that it may be necessary to move away to get the right education. They invest time and resources in maintaining a viable and vigorous local community and strong social networks. They include their children in the daily activities at farms, in shops, crafts or small-scale businesses in order to teach them vital skills for a local 
life. At the same time, however, they all emphasise the importance of education as the best way to ensure their children a good life. Such double strategies are not only a way to adapt to changes on the labour market, but also a way to manage the inherent instability and unpredictability of local social networks. In short, despite their overall satisfaction with local life, they fear that their own way of life and social networks might not be a viable route to pursue for the next generation.

So not only do parents accept that their children will move away; they actually often see it as the best path to pursue, despite realising that the emigration of young people undermines the local life in which they themselves invest so much of their spare time and energy. While considering the risks and dilemmas of the future, they also stress the importance of day care, school and upper-secondary education as means to keep the choices open until the children can decide for themselves. The strategy seems to be that by attending these institutions, their children gain not only the skills and contacts needed to manage locally, but also the tools needed to follow the path of education.

\section{Young Children's use of Local Experiences}

Our observations in two different childcare centres reveal that young children are inspired by local practices. This was particularly true at the kindergarten in the village which we studied, where the children were involved in various play activities that drew on their experience of adult work processes and leisure activities. The following example is indicative in this regard:

A group of 5-year-old boys are going back and forth from a sandpit to a playhouse while discussing the character of the project they are about to do. After a while, they agree that they will build a police station with a prison.

Willum: We need more cement! Marius! Get some more cement! You need to work!

Kasper: Yes, we need more cement. Workers work hard! We need to wall the prison up so the thieves can't look out.

Felix comes by and asks if he can join in.

Kasper: You could be a policeman who drove the thieves to the police station. But we need to build it first. We're busy.

Willum: When will it be finished?

Kasper: It takes a whole day to build a prison. 
Willum: Here we put up shelves. There needs to be a police alarm.

Kasper: Yes, and there must be hooks.

Henrik comes by: It's a mess!

Kasper: It's going to be messy when you're building. Workers sometimes drop things and may not pick them up again.

Willum: Now we have blocked the window.

Marius: Then the glass can't be put in.

Kasper: There's no glass in it. It's concrete.

Willum: We just have to mix the cement.

Kasper: Now we have to mould the concrete. Line [his younger sister], go away.

Marius: Yeah, it's only the working men who can walk on the concrete, not the girls.

Willum: I need a hammer.

Marius: I just made a concrete floor. You mustn't step here.

Kasper: Yes, you may.

Marius: No, it'll be bumpy. It must be perfectly flat.

Kasper: We're levelling it up again. We have a concrete roller. Now we're building a workshop. It has to be a workplace. You mustn't walk where the concrete lacquer has been applied. We must get the concrete over here before it solidifies.

Day after day throughout the six weeks of observation in this kindergarten, the boys were busy digging, levelling, moulding and walling, but also ploughing, weeding, harvesting and driving tractors. They built houses and installed electricity, discussing loudly whether it was most important to use the "excavator" or "tractor" to do the job. Their terminology reflected their interest in physical labour and building, which many of them clearly had heard about from their fathers.

These work activities are not part of what might be referred to as the official agenda of the kindergarten. Although the teachers regard the children's enthusiasm as a positive thing and buy tools that they can use in these activities, they regard them as children's business and not a relevant preparation for school. Although play is generally regarded as important for the individual child's psycho-social development, it is not seen as a subject of educational interest. When all the children are gathered together and in specific educational situations, the staff focus on the importance of letters and numbers, dates and times. As Kasper said one day during 'school hour' in a slightly resigned tone of voice when he was expected to fill colours in 
squares marked with numbers: "I'm afraid you aren't really allowed to work at school". He was supposed to start school just a few months later.

Kasper is right in his prediction. Work as he understands it is not part of the curriculum in any of the schools we visited. In the town of Tønder there are three schools, and in the surrounding area there are three more independent schools (two Danish and one German). These schools have quite different pedagogical and professional profiles, yet they are all obliged to ensure that as many young people as possible continue in high school or vocational training. This goal is stated in the national Danish legislation - but it is also the policy of the local municipality to ensure educational progression after compulsory school. This means that kindergartens must prepare children for school, and schools must enable pupils to advance to uppersecondary education and ultimately apply for higher education (elsewhere). In practice, the actual situation ${ }^{1}$ differs somewhat from the official objective, a fact that local politicians have seen as an incentive to boost the school-oriented curriculum as early as possible. This curriculum is directed at teaching children universal knowledge that can translate into various contexts and is not reflecting or directed at local affairs and needs. As pointed out by other school researchers, this is a cause for mixed feelings about school for some children, and especially for those who are most attached to the way of life they are familiar with (Willis 1977; Corbett 2014, Hansen 2014).

The youngest children generally have a close relationship to their physical and social surroundings which is often based on their primary experiences with the way of life and work processes of their families and local community. As illustrated in the example, the work ethos these children demonstrate clearly gives status among peers. However, when they are enrolled in the preparations for school, their local work-related capital is devalued - knowledge of cement, tractors and ploughs is second to reading skills and studious discipline. This shift in values and codes of respectability becomes increasingly manifest as the children grow older, and has implications for the way in which they perceive themselves and others. Like the parents we quoted above, we find that young teenagers face frictions between locality and mobility, work and education, which for some turn into a real dilemma.

$11.6 \%$ of the girls and $14.2 \%$ of the boys in any one cohort do not finish school or pass the final exam. $61.5 \%$ of a cohort continue into high school, and $26.4 \%$ continue into vocational training. High school has a dropout rate of $12 \%$, while vocational colleges have a rate of 34\%. (Kontur Tønder 2017, p. 25; Ministry of Education statistics 2019). 


\section{Choosing a Future}

By the end of secondary school pupils need to decide if they want to pursue further education and whether they opt for vocational college or one of the three high schools in the local area. Teachers and counsellors, family and neighbours ensure that no-one misses the point that further education is vital, and that they must choose an educational pathway. This requires them to make a career plan and ultimately to aim for a profession. Many young people in their mid-teens have no clear idea about what they want to do, so they tend to base their choice on their social relationships here and now or try to postpone their decision by choosing the STX high school, which is believed to open many doors and only close a few.

Generally, the young people attribute various social and disciplinary features to the high schools and vocational colleges in the area. This has an amplifying effect on who chooses what. The choice of upper-secondary education has symbolic meaning for these young people signalling both life attitudes and group affiliation. They have an ongoing reflection about the opportunities that education gives, but even more about the kind of student life each institution and programme represents and what type of person applies for which programme.

Michael, aged 13, who attends an ambitious private school in the town of Tønder, reports:

"Here, after school, I would like to go to HHX [the commercial line] or STX [the classic high school]. Well HHX, I think it works more professionally with economics and all that, while the STX high school, it just seems more cool. And I have also heard that they have the coolest parties. I will probably love the parties. And then I also just think the rooms look more cool. It looks a bit more like something you see in the movies, while HHX is a bit boring, I think".

This example illustrates how the choice of secondary education is seen as a matter of social identity in the sense that it signals who you are, who you want to be with and who you want to be. Such considerations reflect the existence of various forms of symbolic capital (Bourdieu 1986), related either to work processes and exchange relations among local people, or to national or urban status systems associated with educational degrees, urban lifestyles and high-salary jobs. The local know-how and social relations that count in some circles are fundamentally disregarded in others. For instance, when Michael refers to movies and cool parties, he emphasises the attraction of 
specific codes that count in urban youth culture. However, there are other children who explicitly distance themselves from this kind of references and emphasise their attachment to local life. Such contrasts gradually materialise in the choice between the educational programmes, with vocational training and high school becoming opposites in a continuum between local and urban lifestyles or what could be termed local vs. urban forms of social and cultural capital. The social and cultural differences in modes of living and preferences gradually turn into symbolic and institutional boundaries (Lamont \& Molnár, 2002) with consequences for social relations, aims and ambitions.

Pernille, now a young woman who has moved to Copenhagen to study, recalls her experiences with the various groupings associated with the different youth programmes:

"If you chose the STX high school, it was so much - well, we called them 'the hippies', who sat in a circle completely relaxed and played some guitar. (...). And it was very much that type of people who went to the STX high school, and I just couldn't quite see myself in that group, which is why it was very natural that I chose the HHX commercial programme. And it wasn't really because - I'm not a mathematical kind of girl (...) - but I chose it because it was more my social circle who chose the business school".

For some the choice of secondary education seems quite easy - either because they know what they want, or because they know who and what they like to be associated with. For others the choice is much more complicated. The decision is seen as a public declaration of one's social affiliation, but also as a decision about staying in or leaving the local community as well as close family and friends. So even though most people seem to accept the relevance of continued education, the availability of education is only one of the factors involved in the considerations. Identity, social relations, place attachment and (lack of) visions for local futures are at least equally important. Thus, the interviews indicate a number of contrasting value-laden scenarios: moving away and getting higher education vs. staying local with a less ambitious career; getting new relations and an urban lifestyle vs. retaining close relations and a trusted way of living; seeking a secure trajectory established through education vs. the insecurity of the local job market etc. Whatever the choice, it involves making priorities between different kinds of loyalties, moralities and social connections, and between envisioned opportunities and challenges in later life. In short, the choice of upper-secondary education becomes existential and reflects frictions in local life as well as dilemmas within individuals. 
At the heart of the matter stands the question of leaving - or staying in the local community, that is the places and people one is attached to. People who decide to attend a vocational college find it easier to envision a future close to home; but they will also have to decide their future profession at this early stage of life, making a public announcement of a preference for a local lifestyle and the people who live in the local community. In order to avoid such definitive statements and the social consequences which they imply, quite a few of our young informants explain that they opted for high school as a strategy to postpone the decision about what they wanted to do with their lives. They find the various social, educational and geographical implications of an early choice too complicated and definitive; and as high school is generally regarded as the safe route, it appears to be the most sensible solution. As Amalie says, when reflecting on her choice of high school: "I actually chose it because I didn't know what I wanted". For some young people STX high school is the obvious choice because it paves the way to higher education and new opportunities elsewhere. For others it is simply the only way to postpone their decision - to close their eyes to a variety of frictions and dilemmas, but to do so in a respectable way.

\section{High School as a Route to Mobility}

In our endeavour to understand what influences young people's choice of staying or leaving, we became particularly interested in the STX - the classic high school with roots in bourgeois cultural capital - as about $90 \%$ of a student cohort leave the local area after having passed the exams. This figure is much higher than for any other upper-secondary programme of education. Since the purpose of the high school is to prepare students for higher education, it may not be surprising; but the fact that high-school students from commercial or technical lines do not leave the area to the same extent calls for further exploration. Do the students at the STX high school have higher educational aspirations? Or is it only young people who want to leave the local area who apply? Does their choice reflect the educational or occupational backgrounds of their parents? Or is the teaching in high school especially oriented towards other places? As we couldn't find any specific social or class profile of the students here, we looked at the everyday life at the STX high school and asked students and staff about their views on this issue.

Generally, the narratives of both students and staff at STX high schools reflect a socio-geographical perception of values in which major national and international cities stand out as more interesting and prestigious places than small provincial towns. The consequence is that any indication of an 
intention to move away marks one out as a more interesting person than those who announce their willingness to stay. A broad interest in other places, nationally and especially internationally, as well as a willingness to move serve as indicators of symbolic capital - these are markers of distinction that call for respect.

This is seen in Astrid's reply when she was asked what she wanted to do after finishing STX high school:

Astrid: I'm going away.

John: How can you know for sure?

Astrid: Because, uh, it's too small here. So, I'm a little more into something like Berlin.

Caroline also seems convinced that she wants to leave:

Caroline: Well, I would like to live abroad in order to experience a different culture, and because Denmark is such a small country. You know it by heart.

Aghdi, whose siblings live abroad, also stresses his interest in moving away:

I can't see myself living here in two years. When I finish, I'll live in Copenhagen or in a European metropolis.

With a clear distance to his more locally oriented peers, he continues:

There's a huge difference. They haven't had the opportunity to see their siblings travel abroad and study, etc. So it's too big a leap [for them] to think about going abroad to study. I just think they are only thinking that they should go to STX high school and then eventually perhaps move to Aarhus or Copenhagen - that is the standard plan for the future that many people have. Then I also think there are just a lot of them who have no plans at all-just finish high school and take it from there.

Besides illustrating how different types of geographical mobility are ranked, the last example also shows that educational ambitions are associated with personal attributes such as courage and independence. Aghdi invokes a picture in which bold plans bear witness to a wide horizon, while modest and pragmatic ambitions are seen as unambitious and mainstream: the "standard plan for the future", which only extends to the second-largest city in Denmark, Aarhus, only $300 \mathrm{~km}$ away. It becomes clear that the declaration of one's ambition to leave is a question of respectability. In the high-school context, it is more honourable to have the courage to leave the local area; whereas a strong local attachment is regarded as less prestigious, unimaginative and to some extent even immature. 
The statements cited here reflect what Farrugia (2016) has termed 'a mobility imperative' among youth, indicating a general trend world over for young people to look towards the main cities with their offers of higher education, well-paid jobs, a young lifestyle and a culture of consumption. However, this mobility imperative does not only work on the level of the individual - it also reflects more general dominant values that rank places and people (Bourdieu 1996). The urban centres are more prestigious and powerful because they are associated with finance, consumption, culture and highly specialised and well-paid jobs. Implicitly, this hierarchy is integrated in the education system, first and foremost in the culture of the STX high school and in the geographical distribution of higher education institutions. As argued by Corbett \& Forsey (2017), in the organisation of the education system, curriculum, assessments, counselling, teachers' preferences and indeed the whole educational mindset there is a fundamental orientation toward an urban middle-class way of life with an emphasis on individual aspirations and social flexibility. These values permeate the students' beliefs and hierarchies in terms of what is desirable and recognisable. Despite the fact that a local sense of social commitment and attachment is regarded in general as positive in the local setting, the high-school students refer to it mostly as an obstacle which has to be overcome in order to gain success in an urban, middle-class way.

However, 'the mobility imperative' is only part of the picture. Despite the widespread emphasis on the longing for new horizons, we also find doubts and mixed feelings. When they are about to finish the STX high school some students seem hesitant to leave the local area, although we know from statistics that this is exactly what most of them will do in the end (Sørensen \& Holm 2019). Their desire to leave the local community reflects their dreams for the future, but also the changes in their social networks that have occurred during the period of secondary education. While they are attending high school, many of them lose touch with their former comrades due to the time they spend in the high school and the social and cultural divisions between the various programmes. Gradually, they become more and more dependent on their new classmates, only to discover that their social situation changes again when they gain their high-school diploma. At that point they understand that the social network they have invested in during high school disintegrates as classmates begins to realise their plans of mobility. Most students, therefore, face the dilemma of either remaining in a well-established local network with which they are no longer thoroughly integrated, or leaving the local area in accordance with the plans of mobility, which has been the focal point of status during their years in high school. 
In this way, the different statuses ascribed to various places, local activities and educational routes influence the way young people learn to perceive themselves and each other, and what they see as possible and desirable in the long term. Mobility gradually becomes imperative, not only because life elsewhere and in particular in the main cities symbolises a more attractive lifestyle, but also because of the social dynamics and cultural boundaries that have been established among local children and young people as they grow up. Although many students choose the STX high school in order to postpone the difficult decision of declaring their future plans, it turns out that they already made the decision to leave when the choice of high school was made.

\section{Conclusion}

Parallel to the analysis made by Michael Corbett (2007), the intention behind this study has been to understand the way education contributes to the process that convinces young people to leave a specific provincial district in Denmark. By looking at different age groups, we have endeavoured to show the complexities of this process. It reflects not only the curriculum, values and urban orientation of the education system, but also the social dynamics in a changing local society which is struggling with uncertainties of how to secure their future.

Our interviews with young parents have indicated the effort required to build up a social network in a community characterised by social instability - not least due to the considerable number of young people who leave. Despite their own experiences of local opportunities and a high quality of life, these young parents expressed severe doubts when talking about a local future for their children and, thus, adopted a double strategy to ensure their children will have a safe future. They raised their children to become integrated members in local networks and to learn the skills and codes of conduct suited for a local life, while at the same time, they emphasised the need for their children to follow the educational pathway. However, this double strategy works in favour of mobility and, thereby, contributes to the erosion of the local social stability.

In our interviews with children and young people, we documented that they also had a dual perspective, as many of them expressed doubts and a reluctance to move away while also stating a general acceptance of the need for education. As we spoke with different age-groups, it became apparent how perspectives gradually change as children and young people come 
to realise that their choice will have implications for their social position and relations. Whatever choice it will signal a preference for some people, places and sets of status rather than other. Their choice will have a major influence on which of the different competing forms of capital they can invest in, which again will have consequences for their status in the local community.

In this way, social distinctions become part of the process of growing up and aiming for education. In the analysis we focused particularly on the STX high school as the institutional and social dynamics were particularly evident here. The students gradually become disentangled from local networks, they distance themselves from students at other secondary educational programmes in particular those at the vocational lines, and they learn to participate and consume in accordance with the kind of youth culture they experience at the STX high school. In this way, they become still more close to a specific group of age-mates with the same educational profile, and more distanced not only to their former friends but also to local inhabitants in general, to local lifestyles and forms of capital. By the end of STX high school, most students find little reason to stay even if they want to.

Considering the learning to leave processes, we have addressed in this article, we find there is a need for a broader discussion of how the education system can reflect the needs of rural communities and their children, and how it can outweigh the geographical imbalances caused by a strong process of urbanisation. To open that discussion, we suggest that local schools and high schools develop their curriculums with a much stronger sensitivity to local needs for skills and knowledge. Such a curriculum may help children and young people to gain confidence in and acquire skills for a local future, as well as boosting the sustainability of the local communities in the provinces. This entails a decentralisation of curriculum processes, research in the viability of local communities, and strong collaboration between local enterprises, civil society and schools. In general, what is required is a different approach that aims to take advantage of the resources and energy that are to be found in local communities in order to counterbalance the processes of urbanisation and loss of civilian resources that are currently taking place in Denmark and elsewhere.

\section{References}

Bourdieu, P. (1974). The school as a conservative force: Scholastic and cultural inequalities. In J. Eggleston (Ed.), Contemporary Research in the Sociology of Education. London: Methuen \& Co. 
Bourdieu, P. (1986). 'The forms of capital'. In J. G. Richardson (Ed.), Handbook of Theory and Research for the Sociology of Education. Westport, CN: Greenwood Press. Bourdieu, P. (1996). 'Et steds betydning'. In P. Bourdieu, Symbolsk makt. Artikler i utvalg. Oslo: Pax Forlag.

Bourdieu, P., \& J.-C. Passeron (1977/1970). Reproduction in education, society and culture. London: Sage Publications.

Corbett, M. J. (2007). Learning to leave: The irony of schooling in a coastal community. Nova Scotia: Fernwood Pub.

Corbett, M. (2014). Toward a geography of rural education in Canada résumé. Canadian Journal of Education, 37(3).

Corbett, M., \& M. Forsey (2017). Rural youth out-migration and education: challenges to aspirations discourse in mobile modernity. Discourse studies in cultural politics of education, 38(3), 429-444.

Corsaro, W. (1997). The sociology of childhood. Thousand Oaks, CA: Pine Forge Press. Dyck, N. (2002). Have you been to Hayward Field? Children's sport and the construction of community in suburban Canada'. In V. Amit (Ed.), Realizing community: Concepts, social relations and sentiments. London: Routledge.

Farrugia, D. (2016). 'The mobility imperative for rural youth: The structural, symbolic and non-representational dimensions of rural youth mobilities'. Journal of Youth Studies, 19(6).

Gilliam, L., \& E. Gulløv (2019). Children as potential: A window to cultural ideals, anxieties and conflicts. Children's Geographies, published online August 5.

Gulløv, E., \& J. Gulløv (2020). Opvækst i provinsen. Om dem, der bliver, og dem, der rejser. Aarhus: Aarhus University Press.

Hansen, S.J. (2014). At komme fra 'udkanten'. Om sted, stedsans og unges uddannelsesstrategier $i$ et socialt rum under forandring. Ph.d. afhandling, Institut for medier, erkendelse og formidling, Københavns Universitet.

Tilmelding til ungdomsuddannelser - elevernes bopælskommune. Online: https:// uddannelsesstatistik.dk/Pages/Reports/1793.aspx

Tilgang til ungdomsuddannelserne fra 9. og 10. klasse 2017. online: https://www. gl.org/uddannelse/institutioner/soegetal/Documents/Tilgang\%20til\%20ungdomsuddannelserne\%202017.pdf

Lamont, M., \& V. Molnár (2002). The study of boundaries in the social sciences. Annual Review of Sociology, 28, 167-195.

Levinson, B.A., D.E. Foley, \& D.C. Holland (Eds.) (1996). The cultural production of the educated person: Critical ethnographies of schooling and local practice. Albany: SUNY Press.

Manzo, L., \& P. Devine-Wright (2014). Place attachment: Advances in theory, methods, and applications. London: Routledge

Massey, D.B. (1994). Space, place, and gender. Minneapolis: University of Minnesota Press.

Massey, D.B. (2005). For place. London: SAGE Publications.

Sørensen, E.S., \& Holm, A. (2019). Unge flytter væk fra Danmarks mindste byer - har uddannelse betydning? København: Kraks Fond Byforskning.

Toren, C. (1993). Making history: The significance of childhood cognition for a comparative anthropology of mind. Man, 461-478. 
Willis, P.E. (1977). Learning to labour: How working class kids get working class jobs. Aldershot: Gower.

\section{Authors:}

John Gulløv

University College Copenhagen

Faculty of Education and Social Science

Humletorvet 3

1799 Copenhagen V

Denmark

Email: jgu@kp.dk

Eva Gulløv

Aarhus University

Department of Education

Tuborgvej 164

2400 Copenhagen NV

Denmark

Email: evag@edu.au.dk 